\title{
Chapter 5 \\ Chinese, Japanese, and Korean Writing Systems: All East-Asian but Different Scripts
}

\begin{abstract}
The three East-Asian scripts-Chinese (characters and Pinyin), Japanese (multi-scripts), and Korean (alphabetic Hangul) — are discussed. Under each script, a brief historical account of the given writing system, the key features of the script, and the strengths and weaknesses as a script are described. The commonalities and differences among the three scripts are next discussed. Since it is claimed that Asian orthography, particularly Chinese characters, curbs Asians' creativity (Hannas, 1997, 2003), East-Asian students' performance in international comparison tests is reviewed in comparison to that of American counterparts. Finally discussed are the implications of script differences among the three writing systems for script relativity.
\end{abstract}

Keywords script differences $\cdot$ Chinese characters $\cdot$ Pinyin $\cdot$ Kanji $\cdot$ Kana $\cdot$ Hangul - implications for script relativity

If there is a truth to the "McLuhan Equation" shown above, differences in the "medium" can result in differences in the message conveyed. Based on McLuhan's (1964) words, Federman (2004) notes that "... the medium of language extends our thoughts from within our mind out to others ... since our thoughts are the results of our individual sensory experience..." (p. 2). Therefore, it is possible that the medium of written language plays a role in the extension of our thinking and cognition.

Historically, China exerted a massive impact on Korea and Japan in many respects. With the immense influence of China on Korea and Japan, the three countries have common cultural traditions. According to Taylor and Taylor (2014), Chinese, Korean, and Japanese are closely related geographically, historically, culturally, and racially such that they can be discussed within one book. However, they are not monolithic. Although they share cultural heritage, the three countries have different oral and written languages from one another, except for the partial use of Chinese characters

\footnotetext{
“The medium is the message.” Marshall McLuhan, (1964, p. 9)
} 
in Japanese and Korean ${ }^{1}$ written languages. Since their oral languages do not have common genetic affinity ${ }^{2}$, the adoption of Chinese characters in the Japanese and Korean writing systems was not seamless. Chinese characters or words are used as Sino-Japanese or Sino-Korean words, which means the use of Chinese characters in Japanese and Korean pronunciation, respectively, on top of their native lexicons. For example, the character $\{$ 人\}, that has a shared meaning of a $<$ person $>$, is pronounced differently across the three countries: /rén/ in Chinese, /hito/ in Japanese, and /in/ in Korean. Possibly due to the differences in both oral and written languages, the people of the three countries exhibit differences in many aspects, even though Westerners tend to lump the people together by physical appearance.

This chapter mainly discusses the three East-Asian scripts-Chinese, Japanese, and Korean-in terms of the medium of written language. These East Asian scripts are clear deviations from the monogenesis hypothesis in which all scripts in the world are assumed to stem from one writing, the Sumerian script. Sampson (2015) notes that "[b]y now... the argument against monogenesis is conclusive" (p.57). Each of these three scripts bears significant implications for literacy and their effects. The extent to which commonalities shared among the three scripts as well as major differences among them cannot be found in any other three languages in the world. Sampson (2015) notes that Korean is "much more different from Chinese than one European language is from another" (p. 144). This is also true for the lack of typological affinity between Chinese and Japanese. Although Sampson's (2015) reference was made to spoken language, the same extends to written language. Despite the differences among the three scripts, Chinese script was not only ancestral to the Japanese writing system, but also the motivation for the invention of the Korean writing system, Hangul.

Based on their idiosyncratic characteristics, this chapter elucidates how the three scripts are similar and how they are different from one another. Chinese script is first discussed, followed by Japanese and Korean. Given the vast influence of Chinese on Korean and Japanese, Chinese characters are more extensively covered than the other two. Under each script, a brief historical account of scriptal evolution is first provided, followed by the linguistic features of each script. Finally, the strengths and weaknesses of each script are identified.

\subsection{Chinese Script}

China brought itself to the forefront of the entire region of East Asia in antiquity. China invented printing, the compass, gunpowder, porcelain, paper, and silk before the West. Moreover, China had more technological advances than western Eurasia

\footnotetext{
${ }^{1}$ Chinese-derived Hanja are used in Korea. However, the use of Hanja has been discouraged by the government since the 1980s.

${ }^{2}$ Chinese belongs to the Sino-Tibetan language family. It was traditionally considered that Japanese and Korean belonged to the Altaic language family. Recently, a linguistic camp classifies both languages as language isolates. The debate over the language family still continues.
} 
until about A.D. 1400 (Diamond, 1999). According to Sampson (2015), half of all books ever published in the world were written in Chinese before $1900^{3}$. The explosion of publications in Chinese was possibly due to the inventions of block printing around A.D. 600 and movable wooden type printing around A.D. 1040, which was way before Gutenberg's mechanical movable type printing invented in Germany in 1439 (Man, 2000).

Chinese is the most commonly spoken language in the world among over 1.3 billion people (Ethnologue, 2005; Wikipedia.org, 2019). Chinese is spoken by Chinese natives and those who have Chinese heritage in Mainland China, Taiwan, Singapore, Hong Kong, Malaysia, Thailand, and Vietnam, as well as by Chinese immigrants in European countries, North America, and Australasia. The use of the Chinese writing system alone is on par with the use of all alphabetic scripts.

Concerning the representation of written language, Chinese has been considered to comprise pictograms (mainly by nonlinguists; e.g., \{月\} depicting $<$ moon $>$; $\{$ 木 $\}$ depicting <tree $>$ ), ideograms (e.g., $\{$ 一 $\}$ meaning <one $>$; $\{$ 三 meaning $<$ three $>$ ), and logograms (e.g., $\{$ 花 $\}<$ flower $>$; $\{$ 开花 $\}<$ blossom $>$ ). The common designation is a logography (logo = word; graph = written symbol), representing the meaning primarily and the sound secondarily (Taylor \& Taylor, 2014). Based on the feature that a character represents a morpheme in a syllabic unit, a term morphosyllary has been used to refer to the Chinese writing system (Leong, 1997).

Some scholars claim that Chinese characters are inefficient for learning, compared to the alphabet, because it takes long to learn to read in Chinese due to the vast number of characters to master (Hannas, 1997; Man, 2000; Wolf, 2007). Notwithstanding their inefficiency and complexities, Chinese characters have endured for more than 5,000 years. The Chinese writing system is the only one, among all writing systems invented before 1,000 B.C., which is still used by a great number of people in the world. This causes a number of questions to arise: What has made the Chinese writing system endure so long, despite its inefficiency? Is it the case that precedence or tradition surpasses convenience or efficiency? In addition, if it was inefficient, how could Chinese native students excel over their counterparts in the world in reading, as shown in the results of an international test (PISA, 2018)? If there is a truth to the claim of Chinese characters being inefficient and if Hannas' condemnation of Chinese script is justified, how could the Chinese writing system exert an immense influence on the Japanese writing system? This does not fit well with the notion of natural selection. The remaining part of this chapter attempts to address these questions in terms of historical considerations, scriptal characteristics, and cultural compatibility.

\footnotetext{
${ }^{3}$ Man's (2000) assertion based on an estimate by John DeFrancis is even higher than Sampson's estimate (2015), as shown in his remarks "Chinese printed matter exceeded that of all the rest of the world combined" (p. 58).
} 


\subsubsection{A Brief Historical Account}

\subsubsection{The Origin of Chinese Writing}

The emergence of Chinese characters is rich in history and distinctive in writing. Although some archeologists trace the origin of Chinese characters back to about 8,000 years ago, a credible account goes back to the Neolithic times around 5000 to 3000 B.C. (Demattè, 2010; Taylor \& Taylor, 2014). Evidence from the Yangshao culture developed in the middle and lower runs of the Yellow River in northeast China (a.k.a., the cradle of Chinese civilization) shows painted pottery, stone implements, and incised signs in farming communities (Taylor \& Taylor, 2014). Simple linear signs and pictures of animals, such as fish and frogs, resembled characters engraved in oracle bones, which suggests that these Neolithic signs might be the harbinger of Chinese characters.

The earliest full-fledged Chinese writing is considered to have been developed during the period of 1300-1200 B.C. under the Shang dynasty (1675-1029 B.C. ${ }^{4}$ ). Written signs preserved on bronze vessels and divination bones were found in Anyang county, Henan Province in China, which was the last capital of the Shang dynasty (Bagley, 2004). The Anyang writing includes divination inscriptions for oracle texts on animal bones (mainly oxen bones), either interior or exterior turtle shells, bronze inscriptions, and other inscriptions written on shells, jades, stones, pottery, wood, and bamboo slips. Early bronze scripts representing clan names, which were decorative and pictorial, were written with a brush in the varying degrees of thickness (Taylor \& Taylor, 2014). In the early twentieth century, numerous excavations discovered over 175,000 pieces of bones and shells, bearing over 4,500 different characters, in the Anyang area (Taylor \& Taylor, 2014). Although the Chinese writing system has evolved for more than 3,000 years, there has been little change in the style of writing, except for the simplification of characters ( $\mathrm{Lu} \&$ Aiken, 2004).

\subsubsection{Debate over the Origin}

Although the Anyang evidence is the main interpretation of the origin of Chinese writing, it is still uncertain when, where, why, and how the Chinese script was invented, because it is possible that archaeological evidence and records of preAnyang inscriptions have not yet been discovered, have perished, or have been nonexistent. The explanation of the origin of the Chinese script makes three assumptions. The first hypothesis is stimulus diffusion, meaning that footsteps toward the Chinese written signs can be traced back to Mesopotamia. This hypothesis is open to

\footnotetext{
${ }^{4}$ The ruling period of the Shang dynasty varies across resources (e.g., According to Bamboo Annals, the Shang dynasty ruled from 1556 to 1046 BC). The years reported in this chapter are based on the Xinhua Dictionary (新华字典), which is widely considered a reliable source.
} 
questions. Deringer (1996) claimed that "[t]he general conception of writing might perhaps have been borrowed, directly or indirectly, from the Sumerians, but not a single sign taken from the Sumerian system can be found. A dependence on Egyptian hieroglyphics is still more unlikely" (p. 66).

The second hypothesis, which is the oldest and most persistent interpretation, is that the precursors of the Anyang script were lost, and we can only assume the trajectory based on clan signs on Anyang bronzes. For example, some early oracle inscriptions on bones disappeared with the collapse of the Shang dynasty (Deng, 2018).

The third hypothesis is a sudden invention of full writing with no archaeological trace. This hypothesis posits that a few gifted officials (perhaps diviners) discovered the value of a sign system that could represent oral language and invented full writing without evolutional footsteps (Bagley, 2004). A legendary tale is actually available to fulfill this line of assumption as follows.

Long, long ago, in the golden age, there was a dragon horse which came up out of the Yellow River with curious symbols traced upon its back, and revealed them to Fu-hi (the first of China's legendary primeval emperors). This potentate copied them and thus acquired the mystical characters, which later became the skeleton of I King [I Ching or Yijing; Book of Changes], the Canon of Changes, one of the Five Canons [Confucian classics]. And under the third primeval emperor, Huang-ti [Huang Di], the minister Ts'ang Kie proceeded further along the path of invention and fashioned the first primitive characters, by copying footmarks of birds made in the sand. (Karlgren, 1923, p. 32, cited in Taylor \& Taylor, 2014, p. 36)

The competing hypotheses regarding the origin of Chinese writing (i.e., gradual evolution vs. sudden invention) raise questions about the dynamics and timing of the development of Chinese writing. They also raise a question on the nature of writing as the function of social and cultural phenomena. An independent development of a script typically takes a form of evolution over time. As shown in the cases of Mesopotamia and Egypt, writing is likely to have developed from an earlier sign system by undergoing an extended period of evolution before establishing the status of an efficient tool of language-recording (Demattè, 2010). Like the Korean writing system, Hangul, it is possible that a new writing system is invented out of the blue as a result of top-down governance or as a secondary writing system that complements the primary writing. However, this has been scarce in history.

In favor of the view of a gradual development rather than a sudden invention, Demattè (2010) used four criteria to identify valid evolutionary evidence for Chinese as follows: (1) intentionality and structural coherence of shapes and systematic use, (2) morphological relationships with bronze and bone scripts of the Shang dynasty, (3) an expansion of regional systems over time, and (4) emergence out of the relative socio-political complexity. Based on these criteria, Demattè (2010) concludes that the Chinese writing system evolved from Dawenkou, Liangzhu, and Shijiahe graphs. The forms and usage patterns of these graphs indicate that these signs could fulfill the objectives of simple recording tasks without phonology and syntax. Although it is debatable whether these three signs meet the definition of writing, Demattè (2010) argues that Dawenkou, Liangzhu, and Shijiahe graphs did serve as 
the beginning thread of the mature Chinese writing of the Shang oracle bone inscriptions and that non-linguistic signs also influenced the emergence of the writing system.

Studies of the early Mesopotamian epigraphic corpus indicated that writing was inscribed to control the production of agricultural goods, animal husbandry, and transactions (Bagley, 2004; Logan, 2004; Lu \& Aiken, 2004). Despite the lesser degree of intensity, the Chinese Anyang writing was also used for managing agricultural bases, craft enterprises, and commercial applications. The earliest archeological evidence for Chinese shows that pottery inscriptions, including the numeric information of products and transactions, had the highest frequency of occurrences, suggesting that the purpose of early writing was for counting and book-keeping ( $\mathrm{Lu}$ $\&$ Aiken, 2004). One difference from the Mesopotamian writing was for divination purposes, such as the genealogies of ancestors who received sacrifices and the schedules of sacrifices as well as the king's military campaigns (Bagley, 2004). As full writing is the byproduct of social and political functions as well as activities of administrative applications, ownership assurance of goods, divination records, and royal display were likely to be a collective impetus for the development of Chinese writing.

\subsubsection{A Road to Modern Characters}

Following the Shang dynasty, the Western Zhou dynasty (circa 1046-771 B.C.) reigned, followed by the Eastern Zhou dynasty (Taylor \& Taylor, 2014). The Eastern Zhou dynasty was broken down into two periods: Spring and Autumn (770-476 B.C.) and Warring States (475-221 B.C.). During the Warring States period, society went through significant changes as the powerful lost their power, aristocratic privilege, and hereditary ruling class. After the powerful lost control over the monopoly of writing, non-aristocrats started to use writing. As a result, a variety of script styles were developed in different Warring States. When the Warring States was unified in the third century B.C., the first emperor, Qin Shi Huang (a.k.a., Qin Shi Huang Di) ${ }^{5}$, strived to standardize the varied shapes of characters used at the time in a small-seal script (xiaozhuan) by simplifying the traditional Western Zhou great-seal script (dazhuan). The small-seal script was used mainly for inscriptions on stones and formal engravings (Taylor \& Taylor, 2014). The Qin emperor's standardization of Chinese characters served as a catalyst for unifying Chinese people who spoke diverse dialects. The emperor was the first monarch who could read and required literacy to be included in the regimen of emperor training.

The small-seal script, which was the orthodox script in the Qin period, was the last form of old Chinese writing. The simplified seal characters evolved into a clerical script (lishu), which was named on the basis of its use by official clerks and got

\footnotetext{
${ }^{5}$ The first emperor's achievement was also recognized in the standardization of coins, weights, measurements, and the expansion of the Great Wall. Taylor and Taylor (2014) note that the word China originated from Qin spelled Ch'in based on the Wade-Giles Romanization system.
} 
popularized at that time with writing on bamboo strips (Bagley, 2004; Taylor \& Taylor, 2014).

In the Han dynasty (206 B.C.-A.D. 220), the modified clerical script paved its way to orthodox writing. As demands for official documents grew greater, writing on bamboo strips was replaced with writing on silk and paper with brushes. The clerical script gradually evolved into the standard script (kaishu) during the late Han dynasty. The advent of printing technology in the late Tang (618-907) and early Song (960-1279) dynasties led to the more prevalent use of the standard script. In handwriting, a shorthand version of the clerical and standard script became highly cursive, called "grass script" (caoshu) describing the "dance of the brush." Among a variety of cursive versions, "modern cursive" (jincao) was the most common. A semi-cursive form of "running script" (xingshu) was also developed, which was one of the two most commonly used scripts in the Tang dynasty, along with the standard script. In modern China, the traditional characters have been simplified several times since 1935, which became the orthodox form of characters.

\subsubsection{Features of Chinese Script}

Sampson (2015) summarizes the features of the Chinese writing system, which are not mutually exclusive. First, syllables are demarcated such that syllabic boundaries are clear and unambiguous. This is different from English in which syllable boundaries are opaque within the word. Relatedly, there is no space used between words. Since each character is written in a square block, sentences are legible without spaces between words. Second, morphemes are co-representative with syllables, as a morpheme generally corresponds to a syllable 6 . Since the minimal writing unit corresponds to the syllable, there is no morpheme available at the phonemic level. This is also different from English in which a fraction of a syllable represents a

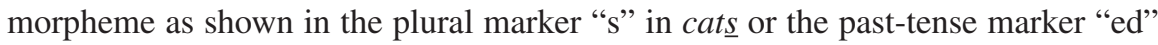
in walked. Third, there are neither inflections that occur at prefix or suffix levels (i.e., no coalescence of roots with affixes) nor morphophonemic alternation. Chinese is not subject to inflections as in Japanese, Korean, and English. For this reason, Sampson (2015) claims that Chinese is an isolating language, in which each word form typically comprises a single morpheme. Last, although each character is written independently, Chinese is not entirely monosyllabic because compound words are the norm and there is the small number of polysyllabic morphemes/words (see footnote 6 in this chapter). Mandarin has fewer than 1,300 distinct syllables (Hannas, 1997). Since no language can survive with only a few thousand monosyllabic words, DeFrancis (1984) notes that the belief of Chinese to be monosyllabic is a myth.

\footnotetext{
${ }^{6}$ Chinese has a small number of polysyllabic morphemes with a pair of sound-meaning compound characters, especially for plants and small animals (e.g., \{蝴蝶\} /húdié/ <butterfly>). Other cases are associated with adjectives (e.g. \{志密\}/tăntè/ <nervous>; \{ 黄澄澄\} /huángdēngdēng/ <very yellow>).
} 
Another feature that is pivotal within the Chinese writing system is the presence of the subcomponent of the character, called radicals (i.e., bushou) including 541 radicals (Chinese Radical Position Frequency Dictionary, 1984, cited in Wang, Perfetti, \& Liu, 2003a). Simple characters can stand alone as independent characters (e.g., $\{$ 子 $\} /$ zi/ <child >; $\{$ 月 $\} /$ yuè/ <moon>) and can be used as the subcomponent of the compound character as the radical (the independent character $\{火\} /$ huǒ/ $<$ fire $>$ becomes $\{\cdots \cdots\}$ located at the bottom of the character as the radical; $\{$ 水 $\} /$ shuǐ/ <water $>$ becomes $\{\mathscr{Y}\}$ located to the left of the character as the radical; $\{刀\}$ /dāo/ <knife $>$ becomes $\{\mathrm{I}\}$ located to the right of the character as the radical). Radicals constitute semantic radicals suggesting meaning and phonetic radicals suggesting sound in the forms of side-by-side, top-to-bottom, closed inside-outside, and open inside-outside. However, semantic and phonetic radicals within characters are not highly reliable in terms of character identification.

There are also compound words. Chinese compound words have systematic ways of combining two characters, and, in general, have three types of morphological construction, including subordinate (one character supports another; e.g., $\{$ 房 型\} /fáng xíng/, house + model, layout of house), coordinative (two characters equally contribute to the meaning; e.g., \{蔬果 $\}$ /shū guǒ/, vegetable + fruits, <vegetable and fruits $>$ ), and attributive (the descriptive character precedes a noun, verb, or adjective; e.g., $\{$ 天价 $\} /$ tiān jià/ sky + price, $<$ high price $>$; $\{$ 速递 $\}-/$ sù dì/ fast + to pass <express delivery>). Kuo and Anderson (2006) further classify the structures of compound words into five types by categorizing the attributive compound words into three types, including subject-predicate (e.g., 公立/gōnglì/ publicestablish, public), verb-object (e.g., 吃饭 /chīfàn/ eat-meal, to eat), and verb/ adjective-complement (e.g., 改进 /găijìn/ change-forward, improve; see also Sun, 2020; Sun, Zhao, \& Pae, 2020).

\subsubsection{Simplified Characters}

A simplification of the traditional script took place by reducing the number of strokes and by changing the shapes of the graphs in order to decrease the complexity of characters and relieve the burden of writing (e.g., traditional characters $\rightarrow$ simplified characters: $\{$ 開 $\} \rightarrow\{$ 开 $\},\{$ 燈 $\} \rightarrow\{$ 灯 $\},\{$ 廣 $\} \rightarrow\{$ 广 $\},\{$ 學 $\} \rightarrow\{$ 学 $\},\{$ 葉 $\} \rightarrow$ $\{$ 叶 $\},\{$ 關 $\} \rightarrow\{$ 关 $\})$. The graph simplification did not make Chinese characters lose the status of being a logography, as Sampson notes " $[\mathrm{t}]$ he simplified graphs are as logographic as those they replace..." (p. 193).

The effort to simplify characters began in the late twentieth century with cursive written text. The first effort for simplification yielded 324 characters introduced in 1935. The government of the People's Republic of China authorized simplified characters that were prescribed in the List of Simplified Chinese Characters for use in Mainland China since the 1950s and 1960s to promote literacy. The People's Republic of China issued the first phase of simplified characters in two documents. The first document was published in 1956 and the second one in 1964. 
The second attempt for simplification was promulgated in 1977 , but it never materialized due to the public's confusion and the unpopularity of the second effort for simplification. The unsuccessful attempt culminated with the Cultural Revolution (1966-1976) which occurred to preserve the communist ideology and Mao Zedong's doctrine by eradicating capitalist and traditional values from the Chinese society. Due to the apprehension created by the Cultural Revolution and Mao's death in 1976, the second phase of simplification was not successful. The government withdrew the second-phase simplification and endorsed the 1964 document with minor changes. The revised List of Simplified Chinese Characters comprising 8,105 simplified characters (including 45 newly recognized characters and 226 characters that were not explicitly acknowledged in the previous document) was officially endorsed for use by the State Council of the People's Republic of China in 2013. Not all Chinese-speaking countries have adopted simplified characters, however, as Taiwan, Hong Kong, and Macau still use traditional Chinese characters.

The method of simplification involved structural simplification by replacing or omitting some components and by adopting new character forms. The simplified form made greater use of phonetic substitutions than the traditional forms. Before the reform, the average of strokes per character was 11 to 12 , depending on characters considered in the sample. Based on the count of 2,000 most frequently used simplified characters, the stroke count dropped from 11.2 (traditional) to 9.8 (simplified) strokes, on average, indicating a $12.5 \%$ drop. The figure rises to $16.2 \%$ of drop in the simplified version for running text (DeFrancis, 1984; Hannas, 1997).

Simplification resulted in more obscure radicals. According to Matthews' Chinese-English Dictionary, 830 characters out of 7,773 entries have lexicographically obscure radicals (Hannas, 1997). This number comprises $11 \%$ of the radicals in the inventory that are obscure, based on lexicographic standards. However, Hannas (1997) asserts that simplification has made readers become less dependent on the morphemic representations of characters because simplified characters lose ideographic illustrations, and paved the way to the phonetic writing addendum, Pinyin.

\subsubsection{Pinyin $^{7}$}

Due to the complexity of characters, an effort to facilitate reading led to a creation of Pinyin (literally <spelling sounds $>$ ), which is a system for transcribing the sounds of Chinese. The Pinyin system was developed in the 1950s and was formally adopted in 1958 as a notational tool. The Chinese government revised it several times. Pinyin uses the Roman alphabet (except the letter $\{v\}$ due to the nonexistence of its sound in standard Mandarin) as well as diacritics for tone to indicate pitch contours rather than the sounds of characters. Since 1979, Western publishers have accepted Pinyin as the standard. This is why the name \{毛澤東\} (traditional) or $\{$ 毛

\footnotetext{
${ }^{7}$ The Chinese transliteration system or phonetic symbol for Taiwanese Mandarin is Zhuyin (注音).
} 
泽东\} (simplified; /Máozédōng/) is now spelled "Mao Zedong" rather than "Mao Tse-tung" (Sampson, 2015). The International Organization for Standardization adopted simplified characters as an international standard in 1982, followed by the United Nations in 1986. Taiwan adopted Pinyin in 2009, but it is partly used for the purposes of international events, not for educational purposes. Another phonetic symbol, 注音符號/注音符号 /zhùyīn fúhào/, is used for transliteration or annotation of sounds only for Taiwanese Mandarin.

\subsubsection{The Number of Characters and Their Complexity}

As for the estimate of characters, there have been efforts to quantify characters in use. The first notable effort was made by the lexicographer Xu Shen who included 9,353 characters in the Shuowen Jiezi ("The Explanation of Simple Characters and Analysis of Composite Characters") in A.D. 121. The second attempt was made by 30 scholars under the Qing emperor Kangxi when the authority defined 47,035 characters to include in the Kangxi Dictionary in 1716. The third notable attempt was made by the Chinese Character Analysis Group in Taiwan when it identified and defined about 74,000 entries in the 1980s, including 49,300 standard characters and additional 24,700 variants (which took different forms of characters but had the same meanings and sounds as standard characters). More recently, The Dictionary of Variant Characters (Yitizi Zidian) included 106,230 entries in 2004 (Taylor \& Taylor, 2014). Hannas (1997) shows another estimate, as in " [t]he Chung-wen Ta-tz' utien (Zhongwen dacidian), which appeared in thirty-eight volumes between 1962 and 1968, held the record at 49,905 characters until eclipsed by the recent appearance in the People's Republic of China of Hanyu dazidian which has nearly 60,000 entries" (p. 131).

The large number of characters indicates that there is no theoretical and practical limit to the number of characters in the writing system. In principle, the increasing number of characters can be infrequently observed because new characters can be created to address newly emerging concepts, new tools, or new discovery (e.g., newly created character $\{$ 摘\}/shāng/ for <entropy $>$, using the existing radical $\{火\}$ /huǒ / < fire > indicating <energy > and \{商\} / shāng/ <quotient> referring to the physics term entropy being defined in a form of division) on top of creating new compound words using existing characters (e.g., \{电脑\} /diànnăo/, electric + brain, $<$ computer $>$ ). A large-scale study conducted by the National Publication Bureau of China in 1975 counted a total of 24,213,955 characters that appeared in various outlets, such as science, newspaper, arts, literature, and politics, but only a little over 6,000 different characters were used for the total number of characters examined in the study (Taylor \& Taylor, 2014). Another estimate shows a similar count; the number of characters currently in use in Chinese is about 7,000 (Zhou, 1987, p. 22, 
Table 5.1. A Wide Range of Character Strokes

\begin{tabular}{|c|c|c|}
\hline Character & \# Stroke & Meaning \\
\hline 一 & 1 & one \\
\hline 木 & 4 & tree \\
\hline 林 & 8 & grove \\
\hline 森 & 12 & forest \\
\hline 龍 & 16 & dragon \\
\hline 鬱 & 29 & melancholy \\
\hline 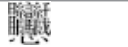 & 64 & exorcism \\
\hline $\begin{array}{l}\text { 龍龍 } \\
\text { 龍 }\end{array}$ & 64 & too talkative \\
\hline
\end{tabular}

Taylor, 2014, p. 53)

cited in Hannas, 1997, p. 132; see also Table 3-5 in Taylor \& Taylor, 2014, p. 49). However, Mandarin has fewer than 1300 distinct syllables (Hannas, 1997), as indicated earlier.

The complexity of characters ranges from one stroke to more than 60 strokes. The character meaning number <one> is written with one horizontal line stroke \{

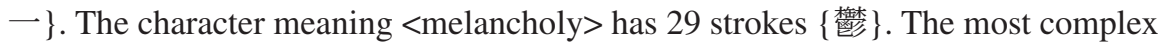
character has 64 strokes, albeit rare usage. Table 5.1 shows characters from the simplest to the most complex. A systematic form of addition is observed in the case of singlet $\{$ 木\} that becomes a doublet $\{$ 林\} and further a triplet $\{$ 森\}. An extreme case of addition is found in the character at the bottom of Table 5.1. The character has duplicates up to four times within a single character with the character $\left\{\begin{array}{l}\text { 龍 } \\ \text { \} }\end{array}\right.$ meaning $<$ dragon $>$ twice at the top and twice at the bottom.

\subsubsection{Strengths and Weaknesses as a Script}

Whatever script a culture adopts, the writing system practically reflects linguistic, psychological, and cultural features of the nation at the surface level. Although a logography can be considered inefficient because of rote-memorization and longer time taken to master than the alphabet (Hannas, 1997; Man, 2000), Chinese characters may fulfill the linguistic needs of spoken Chinese and be conducive to Chinese culture. The logographic characteristics of the Chinese writing system bear several linguistic strengths. Given this is a semi-concluding section for the Chinese writing system, some overlap is inevitable. First, due to its logographic characteristics, in principle, each morpheme in Chinese has its own graph. This means that, in general, the huge number of characters corresponds to the number of morphemes or words in the language. The Kangxi Dictionary of 1716, which 
was the largest Chinese dictionary, contained about 47,036 graphs. In comparison, the Oxford English Dictionary included "less than a third of the period covered by a major Chinese dictionary" in the eighth century (Sampson, 2015, p. 194). The large number of characters to learn requires the learner to take unbearable time until mastery. There may be a trade-off, however. Mattingly (1972) notes that phonographic writing systems, such as English, may show “... more reading successes, because the learning time is far shorter, but proportionately more failures too, because of the greater demand on linguistic awareness" (p. 144). If this is true, the time and effort to learn to read in Chinese may be rewarding because an analysis for syllabic parsing and a synthesis of letter clusters to make sense of a word are not necessary when decoding Chinese characters. Based on Mattingly's (1972) statement, reading Chinese characters, once they are acquired, does not require linguistic awareness of subsyllabic units, such as phonemes, onsets-rimes, or bodies-codas, because it is unnecessary; as a result, it may lead to efficient reading overall by going through direct processes without assembling processes of consonant and vowels. Notably, an international comparison of students' achievement in reading constantly shows Chinese students' reading success (this is revisited in a later section of this chapter in more detail). If there is a truth to Mattingly's argument, the outstanding performance of Chinese students would not be accidental. Undoubtedly, the payoff for Chinese would be the cultural dedication to learning at home and school.

Second, in principle, a Chinese character represents a morpheme such that each morpheme is an invariant of the syllable, except for the small number of polysyllabic morphemes. The nature of monosyllabic morphemes allows for no theoretical limit to how far the inventory of characters can expand (Hannas, 1997). This is evidenced by about 60,000 entries of characters in Hanyu dazidian (Hannas, 1997). Due to its self-sufficient nature of morphology, Chinese did not have to borrow morphemes from other languages to any significant extent (Sampson, 2015).

Last, the writing orientation of Chinese characters offers greater flexibility than that of English. Since they are written in blocks, Chinese characters can be written either horizontally or vertically depending on space availability or the author's intention. Although the left-to-right writing direction has been the norm since $1949^{8}$, characters used to be written vertically right-to-left across the top of the page until the later time of the Qing Dynasty (A.D. 1892).

As for the weaknesses of Chinese characters, the most obvious drawback has to do with the large number of individual tokens and the complexity of their signs. The large number and the complexity of Chinese characters make children take much more time to learn to read than any other written language. In general, it takes six years for children to learn to read in Chinese (The Curriculum and Teaching Materials Research Institute, 2009). In response to the challenge of mastering such

\footnotetext{
${ }^{8}$ Vertical writing direction still remains in Taiwan, especially newspapers and magazines, along with the use of horizontal text.
} 
a large number of characters, the Ministry of Education of the People's Republic of China (2011) published the Curriculum Standards for Chinese Characters in Compulsory Education, which spelled out the numbers of characters that were expected for students to acquire at different grade levels. Grades 1-2 are expected to be able to read 1,600 and write 800 commonly-used characters; Grades 3-4 are to read 2,500 and write 1,600 characters, cumulatively; Grades 5-6 are to read 3,000 and write 2,500 characters accumulatively; and Grades 7-9 are to read 3,500 characters accumulatively.

Inputting logographs into computers or electronic devices is not as easy as letters or graphs in the alphabet (Sampson, 2015). In order use computers or devices, individuals first type the Pinyin for the character of interest and then select the proper suggestion from the pop-up bar with a mouse or select the number associated with a suggestion to enter it. The speed of typing graphs or words per minute is quite comparable with that of European-language typists (Sampson, 2015). However, non-professional typists or learners of Chinese apparently go through an extra-step in Chinese typing.

Another shortcoming may be the large number of homophones, although it is difficult to consider this a weakness. Since Chinese characters represent more than speech, Chinese users can distinguish sight words that have the same sound quality using different tones. A homophone\{谐音\} /xié yīn/ in Chinese refers to words that have the same pronunciation but different meanings, origin, or word form. Due to the use of tones indicating the meaning of the spoken word, Chinese has an abundance of homophones. Perfetti, Liu, and Tan (2005) note that "[m]odern-day usage incudes 420 distinct syllables (disregarding tone) mapped onto about 4,574 characters ... on average, 11 characters share a single pronunciation ... Tone disambiguates a large number of these cases, but ample ambiguity remains (about four homophones for each character)" (p. 44). Table 5.2 shows an extreme case of the same sound with different tones. It is a 64-character story using a one-sound word / shi/ with different tones. The title, story, and its translation are shown in Table 5.2. below.

Regardless of strengths or weaknesses, pragmatically, a relatively small number of characters accounts for most print materials. This makes Chinese more accessible to learners of Chinese because they can identify characters or read Chinese with a mastery of a small segment of the character inventory. DeFrancis (1984) analyzed a corpus of 900,000 characters of written texts to find that the most frequently used 100 characters account for $47 \%$, and 1,100 characters accounted for $90 \%$ of the text. Of 30,000 characters drawn from nine different types of publications, 1,017 characters accounted for $90 \%$, and well-chosen 4,000 characters accounted for $99.8 \%$ (Hannas, 1997). Recently, the Ministry of Education of the People's Republic of China (2013) published a list of commonly used characters in modern Chinese, including 3,500 characters in the first tier, 3,000 characters in the second tier, and 1,605 characters in the third tier, totaling 8,105 characters. The estimates of DeFrancis (1984), Hannas (1997), and the Ministry of Education of the People's Republic of China (2013) consistently show the small number of characters used in practical usage. 
Table 5.2. An Example of a One-Sound Word with Different Tones in a Story

Original Story Yuen Ren Chao (1930)

石室詩士食獅史 (original title by Yuen Ren Zhao) [施氏食獅, widely used title)]

石室詩士施氏, 啫獅, 誓食十獅。 施氏時時適市視獅。十時, 適十獅 適市。是時, 適施氏適是市。施氏 視是十獅, 恃矢勢, 使是十獅逝 世。氏拾是十獅屍, 適石室。石室 濕, 氏使侍拭石室。石室拭, 氏始 試食是十獅屍。食時, 始識是十獅 屍, 實十石獅屍。試釋是事。
Translation

Story of Stone Grotto Poet: Eating Lions ${ }^{\mathrm{a}}$

A poet named Shi lived in a stone room. He was fond of lions and swore that he would eat ten lions. He constantly went to the market to look for ten lions. At ten o'clock, ten lions came to the market, and Shi went to the market. Looking at the ten lions, he used his arrows to make the ten lions dead. Shi picked up the corpses of the ten lions and took them to his stone room. The stone room was damp. Shi ordered a servant to wipe the stone room. As the stone den was being wiped, Shi began to eat the meat of the ten lions. During the meal, he began to realize that the ten lion corpses were in fact ten stone lions. He then tried to write down this story

\section{Characters in tone variations}

\begin{tabular}{|c|c|c|c|}
\hline \multicolumn{2}{|c|}{ Shi, First tone } & \multicolumn{2}{|c|}{ Shi, Forth tone } \\
\hline 詩 & poet, poem & 室 & room \\
\hline 獅 & lion & 士 & person \\
\hline 施 & name, apply & 嗜 & to have the habit of \\
\hline 失 & lose & (施)氏 & demonstrative \\
\hline 屍 & carcass & 誓 & swear, pledge \\
\hline \multirow[t]{2}{*}{ 濕 } & damp & 適 & arrive, adapt, suitable \\
\hline & & 是 & yes, this one \\
\hline \multicolumn{2}{|c|}{ Shi, Second tone } & 視 & look, see \\
\hline 識 & $\begin{array}{l}\text { know, } \\
\text { knowledge }\end{array}$ & 恃 & apprehend, depend \\
\hline 石 & stone & 勢 & situation, power \\
\hline 食 & eat & 逝 & leave, pass \\
\hline 十 & ten & 世 & world \\
\hline 時 & hour & 市 & market \\
\hline 拾 & to pick up & 拭 & wipe, clean up \\
\hline \multirow[t]{2}{*}{ 實 } & true, reality & 試 & try \\
\hline & & 釋 & explain, record \\
\hline \multicolumn{2}{|c|}{ Shi, Third tone } & 事 & thing, event \\
\hline 史 & story & & \\
\hline 使 & order, send & & \\
\hline 始 & start & & \\
\hline
\end{tabular}

aThis title was the original title written in English by the author Yuen Ren Zhao (1930). 


\subsection{Japanese Multi-Scripts}

Japan is composed of four main islands, comprising Hokkaido, Honshu, Shikoku, and Kyushu, as well as numerous small islands surrounding the southeast of the Korean peninsula in the Pacific Ocean. Its population consists of 127 million people, which is 2.5 times more than that of South Korea.

Rather than inventing their own writing system, the Japanese adopted the Chinese writing system on a massive scale, resulting in Chinese characters being ancestral to Japanese scripts (i.e., Kanji, \{漢字\}; literally <Chinese characters $>$ ). In the process of borrowing the Chinese writing system, the Japanese modified the original Chinese pronunciation to integrate the sounds of the Japanese language into writing. However, Japanese oral language is very different from Chinese in terms of phonological, morphological, and syntactic features with no genetic ties to it. Due to the typological difference between the two languages, the process of borrowing Chinese characters to encode Japanese oral language was not smooth. The end-result was "a mixed system, partly logographic and partly phonographic" (Sampson, 2015, p. 208).

Simply based on the complexity involved in the mixed system, DeFrancis (1989) asserts that the Japanese "ended up with one of the worst overall systems of writing ever created" (p. 138). Sampson (2015) argues that there is no rival to Japanese writing in complexity among both ancient and modern scripts. Coulmas (1989) also notes that the Japanese script is "... to be the most intricate and complicated writing system ever used by a sizable population” (p. 122). Sproat (2010) adds an account that "Japanese is a complex system, certainly the most complex writing system in use today and a contender for the title of the most complex system ever" (p. 47). Fischer (2001) also joins the line of the assessment of the Japanese writing system to be the most complicated form of writing ever devised. Even a Japanese senior diplomat who later became the Minister of Education, Viscount Mori Arinori, declared that the whole language system of Japanese, both oral language and written language, should be abandoned, and that English should be spoken and written instead (Sampson, 2015).

The Japanese's attempt to develop their own script was virtually absent from ancient Japanese society. Sampson (2015) provides a justification as to why the Japanese "never made a clean break to a different kind of script" (p. 208). He attributes the Japanese's lack of attempts to have their own script to the Japanese culture, which was shaped by an aristocratic class during the period of the script development. The aristocratic class had more interest in defining and producing civilized cultural norms than values and goals placed in reading and writing. As a result, Japanese culture became delicate and intellectually profound rather than openly practical (Sampson, 2015). 


\subsubsection{A Brief Historical Account}

There are three main types of scripts used in Japan: Kanji, Kana, and Rōmaji \{ロー マ字\}. Kanji are a Chinese-derived script. Kana are a supplementary script and have two subtypes: Hiragana and Katakana. Rōmaji are a phonemic alphabet mainly used for loanwords. If Arabic numerals are counted in the classification, Suji, \{ 数 字 $\}^{9}$ would be the fourth type. A brief historical review of Kanji and Kana development is in order.

\subsubsection{Kanji}

The earliest writing in Japanese in the form of Chinese classics dates back to the fourth century when the great cultural influx took place from the Paekje (or spelled as Paekche or Baekje) kingdom of Korea. Due to the geographical location, Korea served as an intermediary of cultural transmission between China and Japan. As the nation was unified in the late fourth century, the Japanese became politically and socially stable and were ready to accept Chinese culture. Among objects such as seals and bronze mirrors that had Chinese characters inscribed, a sword engraved with a text written in characters is still preserved in a shrine in Japan, which was sent by the Paekje kingdom in the late fourth century (Taylor \& Taylor, 2014). In the $6^{\text {th }}$ and $7^{\text {th }}$ centuries, Sinitic culture, including Buddhism, Confucianism, medicine, calendar, and arts and crafts, was ushered into Japan via Paekje scholars (Frellesvig, 2010). Aristocrats, high-ranking officials, and Buddhist monks played an important role in getting Chinese culture permeated into Japanese lives on a large scale between the seventh and eighth centuries. As the state needed many literate officials, an institute called the Daigakuryō <the University $>$ was founded to train future officials (Taylor \& Taylor, 2014). Two history books, the Record of Ancient Matters (Kojiki, A.D. 712) and the Chronicle of Japan (Nihon Shoki, A.D. 720), were written in Kanji in the eighth century. Kanji was solely used as the script until the two forms of Kana syllabary, Katakana and Hiragana, were created to supplement Kanji in the ninth century.

Although about 50,000 Kanji characters were listed in the Great Sino-Japanese Dictionary, a far smaller number of Kanji is commonly used. Taylor and Taylor (2014) report that 5,000 different Kanji were used in Japanese literature according to a study conducted in 1981. In newspapers and magazines, fewer than 3,000 Kanji are used, and, of these 3,000 Kanji, 2,000 characters account for about $99 \%$ of its use.

\footnotetext{
${ }^{9}$ Precisely speaking, Suji, 数字, have several referents according to different numeric systems: アラビア数字 referring to Arabic numerals (e.g., 1, 2, 3), 漢数字 Chinese numerals (e.g., 一、 二、三、四), and ローマ数字 Roman numerals (e.g., I, II, III).
} 
Kanji are associated with dual-reading or dual-pronunciation: (1) On'yomi reading (On Chinese reading) and (2) Kun'yomi reading (Kun Japanese reading). For example, the character $\{$ 花 $\}$ meaning <flower $>$ has two readings: /ka/ in On reading and /hana/ in Kun reading. On top of these dual readings, in the old days, Kanji were read with the multiple sounds. For instance, the character \{生\} had six meanings (i.e., <life >, <birth>, < growth>, <physiology >, <pupil>, and <raw>) and was read in 19 different sounds (10 official sounds, 2 unofficial sounds, and 2 unusual Kun readings; see Taylor \& Taylor, 2014, p. 279).

Japan has gone through a series of postwar writing reforms on Kanji use since the mid-nineteenth century. The key reform took place in 1946 with a promulgation of Tōyōkanjihyō \{当用漢字表\}, including a list of only 1,850 Kanji for daily common use with the government's officially approved Kun and $O n$ readings. The reform discouraged the use of Kanji other than those included in the list. Newspapers tried to use the 1,850 Kanji by adding Katakana transliteration in brackets or by writing only Kana instead of Kanji. However, other publications and official documents used Kanji beyond the approved list of Kanji. Accordingly, the government periodically published short supplementary lists to include more "rehabilitated" Kanji that were missing from the 1946 list. Moreover, the 1946 list did not sufficiently cover proper nouns, such as personal names and place names, that were in common usage (Sampson, 2015).

In 1981, the Japanese government issued another guideline, in which Jōyōkanji \{常用漢字\} included a list of 1,945 frequently used characters (see Table 1 in Hannas, 1997, p. 45). Of 1,945 characters, the government limited On reading to 2,187 sounds and Kun reading to 1,900 sounds, totalling 4,087 sounds. This meant that some characters still had multiple sounds due to different $O n$ or Kun readings. Of the 1,945 common Kanji, 1,168 characters have both On and Kun readings, 737 characters have only $O n$ readings, and 40 characters have only Kun readings (Tamaoka, et al., 2002, cited in Taylor \& Taylor, 2014, p. 277). The Jōyōkanji list of 1,945 characters was revised with some additional characters to include 2,136 Kanji in November 2010 (Joyce \& Masuda, 2018).

To make matters more complicated, there are heteronyms that are spelled the same but have different sounds and meanings (e.g., \{lead $\} /$ li:d/ or /led/ in English). For example, the disyllabic Kanji word \{生物\} has different meanings depending on which way it is read: On reading seibutsu meaning "living thing" or Kun reading namamono meaning "raw food."

There are additional notational systems called Ateji ( $\{$ 当て字\}, sound-based assigned Kanji) and Jukujikun ( $\{$ 熟字訓\}, meaning-based assigned Kanji). Ateji are a way of using Kanji for their phonetic values disregarding their meanings. For example, the Japanese word sushi is written \{寿司\}. Neither of the two characters is related to fish or food ( $\{$ 寿 $\}$ means longevity of one's life and $\{$ 司 $\}$ means to administer), but the sounds of the characters accord with the sound of the word sushi. Ateji were phonetically used for native words or loanwords in the past, but recently Katakana are used for loanwords. Jukujikun is another way of using Kanji for their semantic values disregarding their sounds. For example, kesa, a native Japanese word that means "this morning, is written $\{$ 今朝\}. Neither of the two 
characters represents any part of the sound of the word kesa, but the meanings of the characters jointly represent the meaning of the word kesa: $\{今\}$ means now and \{ 朝\} means morning.

As indicated earlier, the Japanese reduced the number of Kanji in 1946. The motivation for reducing the number of Kanji was multifaceted. One explanation is that, during World War II, accidents frequently occurred, mainly caused by army recruits whose Kanji reading skills were not good enough to read weapon manuals. Because of dangerous incidents that were the result of soldiers with the low level of Kanji reading, the army restricted the number of Kanji use for weapon parts to 1,235 (Hannas, 1997). Another account is an economic burden that newspaper publishing industries had to carry in order to stock the full range of Kanji in the press inventory. More recently, the advance of word-processing technology added the burden as well because the keyboard could not afford the large number of graphs. Sampson (2015) forecasts that "while the spoken Japanese language remains essentially what it is now, moving to a phonographic script would be utterly impractical" (p. 230).

\subsubsection{Kana}

Although Kanji had been used for a few hundred years since their first introduction in the fourth and fifth centuries, Kanji was not sufficient to address all sounds of the Japanese language as well as all grammatical morphemes such as particles and postpositions. The major problem stemmed from the typological difference between the Chinese and Japanese languages. As an agglutinative language in which words are composed of multiple morphemes or affixes, Japanese has a considerable number of inflectional morphemes. Although Chinese Kanji were fairly well suited to writing content words, inflections were difficult to effectively notate in Kanji. Therefore, Kana came into existence out of the necessity for a phonograph in addition to Kanji's semantic referents. Kana fundamentally remained as a complementary function rather than an autonomous supplant of Kanji. The foundation for the multiscript writing system was established during the seventh and eighth centuries (Taylor \& Taylor, 2014). The Japanese created supplementary symbols, Kana, in the ninth, which were phonetic in nature. The present Kana system was codified in 1900. The 1946 reform spelled out the rules for Kana usage (Hannas, 1997; Taylor \& Taylor, 2014).

Although how the term Kana was settled can be debatable, the dominant assumption is that the term originated from karina (kari means "borrowed" and na means "name" or "letter") to make a reference to the fact that Kana were borrowed from the sounds of Kanji. Another meaning for kari is temporary, unofficial, or nonregular. Karina ended up becoming Kana after kanna was used for a while. This suggests that Kana are a secondary or second-class script to Kanji (Taylor \& Taylor, 2014).

There are two types of Kana. The first is Hiragana (\{平仮名 $\}<$ easy Kana $>$ or $<$ plain Kana>), which was originally used for informal writing. The second is 
Table 5.3. The Distributions of Different Scripts Used in News Outlets

\begin{tabular}{l|l|l|l|l|l|l}
\hline & Kanji & Hiragana & Katakana & $\begin{array}{l}\text { Punctuation \& } \\
\text { symbols }\end{array}$ & $\begin{array}{l}\text { Arabic } \\
\text { numerals }\end{array}$ & $\begin{array}{l}\text { Latin } \\
\text { alphabet }\end{array}$ \\
\hline $\begin{array}{l}\text { Asahi newspaper } \\
(1993)^{*}\end{array}$ & $41.38 \%$ & $36.62 \%$ & $6.38 \%$ & $13.09 \%$ & $2.07 \%$ & $0.46 \%$ \\
\hline $\begin{array}{l}\text { Magazines } \\
(1994)^{* *}\end{array}$ & $26.87 \%$ & $35.66 \%$ & $15.99 \%$ & $21.49 \% * * *$ & & \\
\hline
\end{tabular}

Note: * Chikamatsu et al. (2000; cited in Joyce \& Masuda, 2018)

** Igarashi (2007; see Table 2.1)

*** The percentage represents a collapsed number out of the three categories.

Katakana ( $\{$ 片仮名 $\}<$ side Kana $>$ or $<$ partial Kana $>$ ), which was originally used for official purposes, such as documents. Each type of Kana comprises 46 signs augmented by two diacritics. Nowadays, Hiragana are more frequently used, while Katakana are mainly used for foreign names and terms recently borrowed into Japanese and optionally used for emphasis and onomatopoeia. Kana are used to notate inflectional affixes, grammatical particles, many adverbs, and loanwords with European origins. In contrast, Kanji are used to write content words, such as nouns including both native Japanese and Sino-Japanese nouns, verbs, and adjectives.

The use of different types of scripts varies according to the purposes of usage. The use of newspapers and magazines shows different proportions of the script types. Table 5.3 displays the distributions of different types of scripts used in news outlets.

There is another notational system. Furigana (small-sized Kana that indicate the proper pronunciation of Kanji characters) is the additional Kana written to the right of Kanji if the text is written vertically or above if the text is written horizontally to clarify the writer's intention. Furigana use declined after World War II with restricted use in children's books. However, the government officially endorsed the use of furigana in documents for adults in 1981 (Sampson, 2015). Recently, Furigana use was extended to indicate English translation to identify the intended meaning in the context. However, furigana are occasionally used in a creative form and cross-linguistic boundaries used by second language learners (Sato, 2018).

\subsubsection{Features of Japanese Script}

There are four types of vocabulary in Japanese: native words, Sino-Japanese words (Chinese-derived words in Japanese pronunciation), loanwords, and hybrid compound words (a mixture of Sino-Japanese and Japanese endings or a mixture of Japanese native words and loan words; Taylor \& Taylor, 2014). These four types tend to be written in different scripts among Kanji, Kana, and Rōmaji. For example, the word \{消しゴム\} /keshi-gomu/ means an <eraser>. The first two syllables \{消 L \} / keshi/ form a nominal verb meaning to erase and is a native Japanese word, 
while $\{$ ゴム\} /gomu/ is katakana, meaning <rubber > or <gum>, which is a loanword from the English word gum. Regarding the loanword goти $\{$ ゴム\}, note that, since the canonical Japanese syllable is CV, the CVC English word gum could not be directly used in Japanese. Therefore, an epenthetic vowel was added to the end of the word gum to make gu-mu, which became/gomu/ \{ゴム\}. Another example is the loanword from the English one-syllable word ham, which becomes a twosyllable word $\{八 厶\}<$ hamu $>$ in Japanese to conform to the norm of CV syllables.

According to Taylor and Taylor (2014), the distribution of the word types based on dictionaries published in 1969 includes 53\% Sino-Japanese, 37\% native words, $8 \%$ loanwords, and 2\% hybrid words (p. 260). Over time, the proportion of loanwords has increased. Specifically, in 1960, the composition of new words was as follows: $3.6 \%$ native words, $40.2 \%$ Sino-Japanese words, $43 \%$ loanwords, and $13.2 \%$ hybrid words. However, the distribution of new words in 1980 was changed into the following: $1.9 \%$ native words, $28.8 \%$ Sino-Japanese words, $57.6 \%$ loanwords, and $11.7 \%$ hybrid words.

There are several features in Japanese, which cannot be found in other languages. First, as discussed earlier, the most conspicuous feature of the Japanese writing system is mixed scripts. The paucity of phonetic clues in Chinese characters led to the use of the supplementary Kana script. Although Western linguists have pointed out the Japanese mixed scripts to be the most intricate and complicated writing system in the world (Coulmas, 1989; Sampson, 2015; Sproat, 2010), the advantages of the Japanese writing system have not been discussed. Notwithstanding the complexity and inefficiency as a writing system, the impact of reading the multi-scripts needs to be addressed.

Second, the Japanese language has a smaller inventory of sounds and syllables than those of Chinese and Korean. The small sound system of Japanese is used to produce a "small inventory of extremely simple syllables" (Taylor \& Taylor, 2014, p. 258), which mostly comprises $\mathrm{V}$ or CV syllables. The Kana characters are used to represent five vowels $(/ \mathrm{a} /, / \mathrm{e} /, / \mathrm{i} /, / \mathrm{o} /$, and $/ \mathrm{u} /)$ and 16 consonants $(\mathrm{p}, \mathrm{t}, \mathrm{k}, \mathrm{b}, \mathrm{d}, \mathrm{g}$, $\mathrm{s}, \mathrm{h}, \mathrm{z}, \mathrm{j}, \mathrm{r}, \mathrm{m} \mathrm{n}, \mathrm{w}, \mathrm{N}$ and $\mathrm{Q}$, where $\mathrm{N}$ represents a syllable-final nasal consonant and Q represents a syllable-final consonant that is a part of a geminate consonant; Taylor \& Taylor, 2014). Japanese does not have closed syllables (i.e., CVC syllables), except when $\mathrm{N}$ or $\mathrm{Q}$ is used in a syllable's final position. The Japanese uses a prosodic unit or phonological unit called a mora, which is a time/weight unit that represents one beat. Like open short syllable ( $\mathrm{CV}$ or V syllables), $\mathrm{N}$ and $\mathrm{Q}$ is counted as one mora, while a syllable with a long vowel (CVV or VV syllables) is counted as two moras ${ }^{10}$ in Japanese. A mora is an important sound unit in Japanese because each mora is represented by one Kana character except when the syllable-initial consonant is palatalized (e.g., \{きや\}/kya/). There are $108^{11}$ moras in Japanese which has fewer syllables than Chinese (Taylor \& Taylor, 2014). Chinese has about

\footnotetext{
${ }^{10}$ Some Japanese linguists residing in Japan do not distinguish moras from syllables, while others distinguish them.

${ }^{11}$ The number of moras varies depending on how moras are counted. An inclusion or exclusion of allophones and obsolete sounds that exist only in scripts makes the difference.
} 
400 syllables, and, if tones are considered, the number rises up to 1,300 syllables (Taylor \& Taylor, 2014).

Third, Japanese has abundant derivational and inflectional morphology as an agglutinative language. For example, the root /mot/ meaning < hold > can have many derivatives as follows: motsu, "hold" (plain); motfimasu, "hold" (polite); motanai, "not hold" (plain); motfimasen, "not hold" (polite); motta, "held" (plain), motfimafita, "held" (polite); motanakatta "did not hold" (plain); motō, "be about to hold" (plain); motfimfo, "be about to hold" (polite); mot fi, "holding" (noun), and motte, "(is) holding" (Sampson, 2015, p. 209).

Fourth, like Chinese, there is no marking for word boundaries. Words are simply written one after another without space between them. Due to the nature of mixed scripts, readers can discern word boundaries according to different types of scripts (i.e., Kanji or Kana), but not from space between words.

Next, before the Chinese simplified their script in the 1950s, the Japanese simplified some of their graphs to reduce the number of strokes. Hence, the simplified characters are different between Chinese and Japanese (e.g., 廣-广-広; 氣-气-気; 關-关-関; 齒-齿-歯; 應-应-応; 單-单-単; 圓-圆-円 in the order of traditional character, Chinese simplified character, and Japanese simplified character, respectively). Compared to the Chinese simplification, the Japanese simplification was minimal (Sampson, 2015). As for the simplified version of Japanese Kanji, the Tōyo Kanji published in 1946 listed 1,850 characters, including 131 simplified forms. They were expanded to about 300 by the 1949 law on character shapes.

Hannas (1997) notes that an average of 3,120 characters are in use in Japanese, which is less than half the number used in Chinese. The most commonly used 1,500 characters account for 96 to $97 \%$ of all appearances of characters in contemporary Japanese magazines, and 2,000 characters represent the coverage of 98.5 to $99 \%$ (Saiga, 1971, cited in Hannas, 1997, p. 215).

\subsubsection{Strengths and Weaknesses as a Script}

The characteristics of the Japanese writing system bear some strengths and weaknesses as a script. As for strengths, first, the comparatively simple sound inventory that includes 108 moras (Taylor \& Taylor, 2014) with simple syllabic structure (mostly CV structure) may be useful for foreigners to learn Japanese as a second language or a foreign language. The simple syllabic structure of CV and V with five vowels and 16 consonants may promote learners to acquire the sound system quickly. Kana, which are moraic units, can visually inform learners of Japanese with proper rhythm, proper prosodic divisions, and proper pronunciations of a Japanese word, whereas Rōmaji can mislead them mainly because of the absence of some sounds in the Japanese sound system (e.g., the Japanese liquid sound is not actually /1/ or /r/, but is an approximated sound between /l/ and /r/).

Second, like Chinese, Japanese can be written either horizontally or vertically. Although the Japanese have not officially given up writing in vertical columns, the 
current trend favors the left-to-right horizontal orientation. While school books and technical materials are typically printed horizontally, general-interest or entertainment books such as novels are still printed in right-to-left vertical columns. A more dominant use of the horizontal orientation in these days results from the default setting of the Japanese word-processor program (Sampson, 2015).

Third, the multi-script system provides learners of Japanese with flexible scaffolding for writing and reading in Japanese. They can write solely in Hiragana if they do not know Kanji. They can write some English words in Katakana if they have not yet mastered the set of Japanese scripts. They can guess the meanings of words based on some basic Kanji characters and some components of Kanji called bushu (radicals). Furigana written in the right or above Kanji characters also provide a cue to the pronunciation of Kanji characters.

Concerning weaknesses, due to the complexity involved in using the multiscripts, learning to read Kanji and the two types of Kana (i.e., Hiragana and Katakana) may require a slightly longer time than other orthographies to gain mastery in reading. Second, the large number of homophones in Sino-Japanese vocabulary can add another complexity, although it is not necessarily considered a weakness (because it can be a mere characteristic of the script). The large number of homophones in Sino-Japanese morphemes and words resulted from the fact that when the Japanese imported Chinese characters, they could not retain tones. As a result, some syllables ought to be simplified to reflect the Japanese syllable structures (e.g., \{ 県\}, \{権\}, \{件\}, \{験\}, \{圈\}, \{研\}, \{券\}, and $\{$ 謙\} are pronounced as /ken/).

Third, Kanji impose obstacles in the way of computerization. However, the Japanese have found a way to accommodate the challenges. They type the onset of the pronunciation of the Kanji character in Latin letters and then select the target Kanji among candidates with a mouse click. It is very similar to the way in which the Chinese type in the keyboard using Pinyin and then select the target Chinese character with a mouse click, a number-key stroke, or an arrow-key stroke. Furthermore, learners of Japanese can take advantage of software that automatically provides Furigana to overcome the difficulty of reading Kanji.

Despite the complexity of the script, Japan has a high literacy rate and low rate of reading disabilities among school-aged children (Taylor \& Taylor, 2014). Sampson (2015) notes “... many aspects of Japanese culture, including its writing, were greatly elaborated - made exquisite and intellectually rich rather than straightforwardly functional" (p. 208). The inefficiency of the multi-script does not prevent Japan from becoming one of the technologically and economically leading nations in the world.

\subsection{Korean Script, Hangul}

Korea is a small country with a population of 73 million including both South Korea (50 million) and North Korea (23 million). The U.S. is about 99 times bigger than South Korea (Texas is 7 times larger than South Korea) and 82 times larger than 
North Korea. Due to its geographical location between China and Japan, in history, Korea not only was a cultural transmitter from China to Japan, but also was a target of the neighboring nations for imperialism. After World War II, Korea was divided into two countries of the Republic of Korea in the south and the Democratic People's Republic of Korea in the north. Unlike the Japanese who massively borrowed Chinese characters, the Koreans enjoy their own script, which is an alphabetic script, Hangul. Although they have different political, economic, and social systems, the two Koreas use the same oral language and written language (South Korea call the script Hangul, while North Korea Chosungul).

Man (2000) argues that, although the perfect alphabet may be a remote ideal, it is possible to have a better alphabet than the Western alphabet. In reference to the Korean writing system, Man (2000) argues that "[w]e know this [to have a better alphabet] because there is an alphabet that is about as far along the road towards perfection as any alphabet is likely to get" (pp. 108-109). He goes on indicating "[i]n its simplicity, efficiency and elegance, this alphabet is alphabet's epitome, a star among alphabets, a national treasure for Koreans...” (p. 109). Sampson (2015) also acknowledges that "Hangul must surely rank as one of the great intellectual achievements of Mankind" (p. 165). This line of recognition started in the 1960s when scholars gave credit for "perhaps the most scientific system of writing in general use in any country" (Reischauer \& Fairbank, 1969, p. 435, cited in Sampson, 2015, p. 143) and "the world's best alphabet" (Vos, 1964, p. 31, cited in Sampson, 2015, p. 143). Hangul successfully enjoys the advantage that the alphabet provides by having the minimum number of graphs necessary to express Korean spoken language unambiguously.

\subsubsection{A Brief Historical Account}

Since old Korea became a unified nation in A.D. 700, the nation evolved into an independent and sophisticated society. Under the influence of China, the old Koreans adopted Chinese culture, trade, literature, and language. However, the adoption of Chinese culture did not go seamlessly because the Korean language has no genetic ties with the Chinese language. Sampson (2015) notes that "Korean is much more different from Chinese than one European language is from another" (p. 144) and "[n]ot only is Korean genetically unrelated to Chinese, but the two languages are different in type" (p. 144). Despite the differences, the Koreans borrowed vocabulary from Chinese and some of them are still used as Sino-Korean words. However, "the grammar is purely Korean" (Sampson, 2015). Korean word order (i.e., SOV syntactic structure) and agglutinative properties are very similar to those of the Japanese language.

In medieval Korea, both woodblock presses and movable wooden type printing methods were used. Although movable wooden or porcelain type printing was invented in China around 1040 (Man, 2000), Korea was the first country in the world to invent a movable metal type printing machine during the Goryo dynasty in 
1377. This was 78 years earlier than the Gutenberg Bible with 42 lines per page published in 1455. The first publication that used the movable metal type printing technology was a book of Buddhist teachings, Jikji, written by a monk named Baekun \{白雲\}. This historical feat had been buried for a long time because a French missionary to Korea took Jikji to France and the book has been in the Collection of the National Library of France since 1890. The credit for the first movable metal printing in the world was finally granted in 1972 when a Korean scholar, Dr. Byungsun Park, found it in the national library in France. In September, 2001, $J i k j i$ was registered in the Memory of the World, which is the UNESCO's worldwide program that strives to record, preserve, and disseminate treasured archive masterpieces and collections on the globe. Unlike wooden block printing that could publish only one book at the same time, movable metal type printing allowed for information to be spread widely. The increasing availability of books revolutionized the accessibility of knowledge that was once reserved to the elite, coupled with the invention of the alphabet which was much easier to learn than logography.

A new dynasty, Chosun, was established in 1392 by escaping from MongolChinese control. Confucianism was adopted as the new dynasty's official ideology. The fourth Chosun king, Sejong, came to reign in 1418 at the age of 22. King Sejong renovated and reorganized a research institute $\{$ 集賢殿\} by recruiting specialist scholars and restructuring rituals and protocols. He revised the calendar, standardized weights and measures, and set the guidelines for the study of history. Of the 308 books he produced, 114 were printed using the movable metal type press method mentioned earlier (Man, 2000). During his 32-year reign, he established the foundations of the dynasty that lasted five hundred years. He is regarded as Korea's best and brightest scholarly monarch, and his statue is at the heart of the city in Seoul, the capital city of South Korea. At the center of his numerous inventions is the Korean alphabet Hangul.

Before Hangul was invented, Chinese characters had been reserved for elites. Ordinary people had used crude writing systems (i.e., Idu \{吏讀\}, for prose transcription or for grammatical markers; Hyangchal ${ }^{12}$ \{鄉札\}, for lyric texts and local letters and poetry; Kugyul, \{ 口訣\} for an annotation of Chinese texts and insertions for oral recitation) that partially adopted the sounds and shapes of Chinese for the writing of their oral language. Despite these indigenous notational systems, ordinary people could not read Sejong's books published using the metal printing press because they were written in Chinese.

King Sejong became increasingly concerned that his books and other written materials could not be read by ordinary people. Several attempts to reapply Chinese characters to the creation of a new script did not work. With a keen understanding of the differences in the linguistic system between Chinese and Korean, he was determined to create a new writing system that would be easy to learn to read. This

\footnotetext{
${ }^{12}$ After Hunminjungum was promulgated, Hyangchal was moribund, but Idu and Kugyul were still in use for a while afterwards.
} 
original idea entailed challenges for persuading the Chinese-speaking scholarbureaucrats and for uprooting the traditions of the dynasty establishment.

In the winter of 1443 , the $28^{\text {th }}$ year of Sejong's reign, a new script was finally devised from its secretive gestation and was published as the Correct Sounds for the Instruction of the People ${ }^{13}$. Sejong's Introduction to <훈민정음> /hun min jung $\mathrm{um} /$ encapsulated his purpose in a classic statement:

The sounds of our language differ from those of China and are not easily conveyed in Chinese writing. In consequence, among the ignorant, there have been many who, having something to put into words, have in the end been unable to express their feelings. I have been distressed by this, and have newly designed a script of 28 letters, which I wish to have everyone practice at their ease and use to advantage in everyday life (Man, 2000, p. 113).

Sejong believed that the script was easy to learn to read and had no doubt about the benefits and capacity to capture all sounds in the universe.

A wise man may acquaint himself with [the graphs] before the morning is over. An ignorant man can learn them in the space of ten days... there is no usage not provided for, no direction in which they do not extend. Even the sound of the winds, the cry of the crane, the cackle of fowl and the barking of dogs-all can be written. (Man, 2000, pp. 113-114).

There has been debate over King Sejong's role in the invention process of Hangul. The first interpretation is a command hypothesis. He might have ordered his subjects of scholars to devise a script that was easy to learn to read. The second is a cooperation hypothesis. This hypothesizes that King Sejong collaborated with his scholar-subordinates in the development of the script. These two views have been widely accepted until recently. A new hypothesis that recently emerged, independence hypothesis, posits that King Sejong himself independently and secretively devised the script ${ }^{14}$ (Yeon, 2010). Although it is impossible to prove this, it was possible that King Sejong experimented by himself the newly designed script to ensure efficiency for learning before publicizing it. This new hypothesis is more convincing in consideration of the delicate diplomatic relations with China at the time when the dynasty's cultural dependence on China was immense. Historical records that are still available show that the group of scholars who were immediate subordinates to King Sejong were against the new script upon promulgation. Based on these factors, the third hypothesis of King Sejong's independent invention is more plausible and gains more weight than the first two. Beyond its first name of the

\footnotetext{
${ }^{13}$ The Korean phrase 훈민정음 /hun min jung um/ has also been translated into the Standard Sounds for the Instruction for the People (Sampson, 2015). The literal translation is the Correct Sounds for the Instruction for the People.

${ }^{14}$ There is a legend associated with King Sejong's scheme that he devised before the official promulgation. The King was concerned about how the new script would be accepted by the public due to the heavy reliance on China and Chinese characters at that time. In an effort to make the new script more acceptable, he concocted a scheme. He wrote each graph he created in honey on a large leave fallen from the tree in the palace garden. When he walked into the garden with his subordinates in the following morning, the King found large leaves with magically etched graphs because insects had eaten the honey and the leaf fiber underneath. He claimed that the graph was brought to them from heaven as a gift.
} 
writing system <훈민정음> /hun min jung um/, the currently used neologism Hangul (literally meaning the Great Script) came to existence in 1910 by a Korean linguist, Ju Sikyung, and his colleagues.

Despite King Sejong's authority and effort to spread the script, the solid establishment of Hangul as an official script in Korea took some time. Bureaucrats and scholars in the Chosun dynasty still kept their Chinese for over four centuries. It was April 7, 1896 when the first newspaper was published in Hangul only. Unfortunately, during Japanese occupation between 1910 and 1945, Hangul use was prohibited under the Japanese imperialism. After Korea's post-war division into two Koreas, South Korea endorsed both Hangul and Hanja (Chinese origin with Korean pronunciation). However, North Korea committed to use Chosungul (North Korea use this word to refer to Hangul) only by abandoning Chinese characters entirely since 1946 under its Communist dictator, Kim Ilsung, the grandfather of Kim Jungeun who is the head of the current regime.

\subsubsection{Features of Hangul}

\subsubsection{Consonants and Vowels}

Korean consonants and vowels correspond to Korean phonemes, unlike Chinese and Japanese whose written unit corresponds to a syllable and a mora, respectively. Clear is the visual distinction between consonant and vowel letters in Hangul. Perhaps the most distinct feature of Hangul is the shape of the basic consonant letters that reflects articulatory properties of the phoneme they represent. When Sampson (2015) classifies Hangul as a featural script ${ }^{15}$, he basically relies on this characteristic of Hangul. Although his classification of phonography into syllabic, segmental, and featural scripts is questionable because of the inconsistent criterion used for the taxonomy, Sampson is on point about Hangul's featural characteristics. The Korean consonants graphically reflect the shapes of the articulatory vocal organs, such as the tongue, palate, and lips when the sounds are articulated.

The formation of consonants was systematic. Starting from the pictographic sign $\{$ $\}, 28$ consonants were created. Given the sign $\{$ ㅁ $\}$ means the $<$ mouth $>$ / $\mathrm{kǒu} /$ in Chinese (/ko/ in Korean), the starting point of the consonant is considerably

\footnotetext{
${ }^{15}$ As discussed in Chapter 4, Sampson's (2015) classification of Hangul as a featural script is problematic because not all graphs meet this description (especially vowels) and because the criterion of the classification is not consistent. He classified the phonographic system into syllabic, segmental, and featural writing. The first two (syllabic and segmental) writing systems are divided by the unit of the script, while the last one, featural, is based on the depiction of graphs.
} 
meaningful. Based on this graph $\{$ $\}$, two additional graphs were created; when the graph $\{\square\}$ is divided in half by a diagonal line starting from the top left corner, it results in two new graphs $\{\neg\} / \mathrm{g} /$ and $\{\llcorner\} / \mathrm{n} /$. The graphs of $\{\neg\}$ and $\{\llcorner\}$ represent the shape of the tongue during articulation, either raised in the back towards the velum or with the tongue blade lowered, respectively. The $\{\bigcirc\}$ graph indicates either the null $(\varnothing)$ onset consonant or the open airstream of nasalization $(/ \mathrm{y} /)$, depending on where it appears in the syllable. Depicting the airstream obstructed around the alveolar ridge, $\{$ 人 $\} / \mathrm{s} /$ is the alveolar fricative consonant. Drawing upon the five base consonants, consisting of $\{\square\},\{\neg\},\{\llcorner\},\{\bigcirc\}$, and $\{$ 人 $\}$, additional consonants were created by adding a stroke or two (i.e., $\{$ 口 $\} \rightarrow\{$ ㅂ $\} \rightarrow\{$ $\} ;\{\neg\} \rightarrow\{$ ㄱ $\} ;\{\llcorner\} \rightarrow\{ᄃ\} \rightarrow\{E\} ;\{$ 人 $\} \rightarrow\{$ 大 $\} \rightarrow\{$ 天 $\}$; and $\{$ O $\}$ $\rightarrow\{\overline{0}\})$. Figure 5.1 shows the systematic gradation in the consonant and vowel formation.

Rooted in practicality, Hangul vowels reflect the notion of Neo-Confucianism. The opposites of yin (meaning the female, passive, dark, wet, and cold principles)

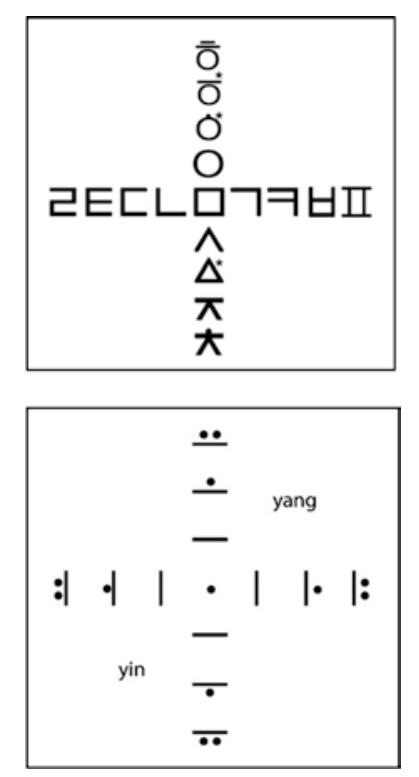

Figure 5.1. Consonant Formulation (top) and Vowel Formulation (bottom) in Hangul Note: * These signs are not currently in use.

Reprinted from Pae (2018) with permission by John Benjamins. 
and yang (meaning the male, active, bright, dry, and hot force) are harmonized within the vowel inventory. The elaboration of three basic universe symbols is shown in the use of a vertical for Man $\{\mid\}$, a horizontal for Earth $\{-\}$, and a circle for Heaven $\{\cdot\}$. The vowel sounds are either 'bright' (yang) or 'dark' (yin) depending on the position or shape of the articulatory organ upon the articulation of each sound. For example, when the <heaven $>$ stroke $\{\cdot\}$ is attached to the right of the $<$ human $>$ stroke $\{\mid\}$ or above the <earth $>$ stroke $\{-\}$, yang vowels are created (i.e., $\{\vdash\},\{\vDash\}$ and $\{\perp\},\{\Perp\}$, respectively, with the $<$ heaven $>$ symbol becoming a little more elongated stroke than the original $\{\cdot\})$. When the heaven stroke is combined with the earth stroke to the left or underneath, yin vowels are created (i.e., $\{-\},\{\neq\}$, and $\{T\},\{\pi\}$, respectively). The use of the three atomic symbols of the dot, horizontal stroke, and vertical stroke under the combinatorial rule results in 21 mutually exclusive vowel letters in total, comprising 10 bases and 11 compound vowels.

\subsubsection{Syllables}

Two characteristics stand out from the syllabic structure of Hangul. First, the union of a consonant and a vowel is a reflection of the yin-yang complementarity in that the consonant sets the articulatory context and the vowel complements it to make the solid sound for a syllable. Hence, neither the consonant nor the vowel can fully function without the other in terms of articulation, although each graph has its sound value. Second, the visual configuration of the syllable is clear and unambiguous to the extent that syllabic parsing within the string of letters is unnecessary. In addition, the segments (i.e., consonants and vowels) are written in square blocks, wherein all the consonants and vowels are packed within restricted formats.

With the combinatorial rule of the consonant and the vowel, 11,172 syllables can be created in Hangul. These comprise 399 CV syllables (19 onsets x 21 vowels) and 10773 CVC and CVCC syllables (19 onsets x 21 vowels x 27 final consonants). Of these possible syllables, 2,350 syllables have high frequency in use, while 8,822 syllables have low frequency in use.

The syllabic unit is similar to those of Chinese and Japanese. Despite the visual similarity among Chinese, Japanese, and Hangul, Hangul is different from Chinese and Japanese in that letters represent the sound of oral language and that a syllable is composed of more than one phoneme/grapheme to represent a syllable (i.e., alphabetic principle). The distinct syllabic block as well as the conformity to the alphabetic principle make Hangul stand out among all scripts used on the globe.

Due to its clear syllabic block, Hangul can be written vertically or horizontally like Chinese and Japanese. When it first came into existence in the fifteenth century, it was written vertically. Until about three decades ago, all newspapers and many books were printed vertically. However, almost all print materials are currently printed in the horizontally linear sequence. 


\subsubsection{Strengths and Weaknesses as a Script}

Questions of "good" or "bad" oral language do not arise in linguistics because the axiom of equal goodness of spoken language has been held (i.e., each spoken language is equally good enough to serve its purpose for the speakers of a particular language). This widespread assumption that "all spoken languages are equally 'good,' equally structurally subtle, equally efficient" is accepted partly for ideological reasons and respectable justifications because "spoken language is in a sense functionally self-defining" (Sampson, 2015, p. 7). However, Sampson (2015) stipulates two conditions that make a writing system "good" or "bad" depending on the answers to two questions below:

- "How efficiently does the system function for those who have already mastered it?

- How easy is it to learn?" (p. 6)

The first condition refers to efficiency for skilled readers and the second is about learnability for emergent readers. Korean Hangul fulfills these two conditions to be a good writing system. Regarding the efficiency of reading Korean, lexicon megastudies projects show that Korean readers' lexical decision rate is the fastest (620 $\mathrm{ms}$ ), followed by $646 \mathrm{~ms}$ for Chinese, $654 \mathrm{~ms}$ for Dutch, $740 \mathrm{~ms}$ for French, and 784 ms for English (see Table 5, Tse et al. 2017; Table 2, Yi et al. 2017). When he promulgated the newly developed script in the fifteenth century, King Sejong stated that smart learners would be able to learn to read within one morning and not-sosmart learners will take about 10 days to master the script. This is indirectly supported by fact that the majority of Korean children master decoding of Hangul at the age of 3 or 4 before kindergarten (Taylor \& Taylor, 2014).

Although there are no empirical data available for the claim of the attrition of literacy skills, my personal experience makes me think that Korean readers may experience a minuscule degree of the attrition of reading rate in Hangul even after no use of the script for a while. I have personally asked many Korean immigrants who have lived in the U.S. more than two decades or who have lived longer in the U.S. than in Korea about their experience of reading Korean. Everybody to whom I have spoken has reported neither trouble nor (perceived) decrease in the reading rate of Korean. In contrast, I have seen many Chinese colleagues who self-report their forgetfulness of Chinese characters with their reduced use of Chinese written text. I also have a similar experience with Chinese characters. I was able to read and write about 1,000 characters while I was in high school in Korea, but the ability significantly declined with no use and no exposure to Chinese characters for a while in the U.S. This anecdotal account can provide a good basis for an empirical study of the attrition of reading skills among speakers of the three East-Asian languages.

Regarding the weaknesses of the Korean writing system, I cannot come up with a shortcoming as a script. The Korean oral language is rather complex. However, the 
writing system serves King Sejong's original purpose well (i.e., to combat illiteracy through a script that is easy to learn). The high literacy rate in Korea proves, in a sense, the script's effectiveness. The invention of Hangul was the point of departure from the history of cultural and linguistic dependence on Chinese. Had it not been for Hangul, the Koreans might have been in the continuation of the past under immense Chinese influences.

\subsection{Commonalities and Differences among the Three Scripts}

\subsubsection{Commonalities}

The three scripts of Chinese, Japanese, and Korean have commonalities in such a way that syllabic units are clearly distinguished in text. Due to their unambiguous syllabic units, the three scripts can be written either horizontally or vertically depending on space availability or for aesthetic purposes. This flexible writing orientation cannot be found in Western scripts.

Another commonality has to do with an artistic expression of scripts. Calligraphy is one of the major art forms surrounding the East-Asian scripts. The use of the brush for calligraphy makes the hand move up and down easier than moving horizontally; therefore, the aesthetic embellishment through calligraphy is typically found in the vertical form, which is facilitated by the syllabic configuration in a block. Although Western alphabetic scripts have various fonts or show aesthetic qualities in handwriting, the degree of flexible aesthetic touches associated with scripts are not similar to calligraphy.

\subsubsection{Differences}

The main source of variations among the three scripts of Chinese, Japanese, and Korean stems from the differences in their spoken languages (Sampson, 2015). The differences among these three scripts primarily come with the typological difference. In short, the Chinese writing system is a logography or a morphosyllabary. The Japanese writing system is multi-scripted. The Korean writing system is an alphabet. Due to the dominant syllabic structure and syllabic functioning, Korean is also considered to be an alphasyllabary (Taylor \& Taylor, 2014). A term of alphabetic morphosyllabary is also proposed to capture all characteristics involved in the Korean writing system. Given that more than $70 \%$ of the Korean lexicon comprises Sino-Korean words, the term alphasyllabary does not address the considerable morphological component embedded in the Korean writing system (see Pae, Bae, \& Yi, 2020). 
Relatedly, due to the difference in the nature of script, a difference is also observed in the number of syllables. Japanese has a little over 100 syllables. Chinese has about 400 without counting tones (with tones, it has about 1,300 syllables; Taylor \& Taylor, 2014). Resulting from the comparatively limited number of syllables, homophones are more prevalent in Chinese and Japanese than other scripts. Korean has more than 11,000 possible syllables, although 2,350 syllables are frequently used.

Another difference among the three scripts is syllabic structures. Compared to English, the three scripts have much fewer syllabic structures. Chinese has five, Japanese has three, while Korean has five. The classification can be different when another criterion is applied. Table 5.4 shows the syllabic structures of Chinese, Japanese, and Korean, compared to that of English.

Table 5.4. A Comparison of Orthographic Syllabic Structures among the Three East-Asian Languages in Contrast to English

\begin{tabular}{|c|c|c|c|c|}
\hline Syllabic Structure & English & Chinese $\dagger$ & Japanese $\dagger$ & Korean \\
\hline V & $\mathrm{a}$ & 啊 /a/ auxiliary tone word & $\begin{array}{l}\text { 絵 /e/ } \\
<\text { picture }>\end{array}$ & $\begin{array}{l}\text { 아**/a/ (null } \\
\text { word) }\end{array}$ \\
\hline $\mathrm{CV}$ & to & 打 /dă / <hit> & 眼 /me/ <eye > & 가 (/ga/ null word) \\
\hline $\mathrm{VC}$ & an & $\begin{array}{l}\text { 按 /àn/ <press > (the } \\
\text { button) }\end{array}$ & & 안**/an/ (inside) \\
\hline $\mathrm{CCV}$ & the* & $($ 吃 /chī/ <eat>) & & \\
\hline $\mathrm{CVC}$ & set & 看 /kàn/ <look> & $\begin{array}{l}\text { 本/hon/ } \\
\text { <book> }\end{array}$ & 각 /gak/ (angle) \\
\hline $\mathrm{CVCC}$ & west & & & 값*/gab/(price) \\
\hline CVVC & read & & & \\
\hline CVCCC & worst & & & \\
\hline CVCVCC & silent & & & \\
\hline $\mathrm{CCVC}$ & scan & & & \\
\hline CCVCC & sprint & & & \\
\hline CVCCC & birth* & & & \\
\hline CCVCC & thing* & & & \\
\hline CCCVCV & strike & & & \\
\hline CCVCCC & graphs* & & & \\
\hline CCCVCC & strong* & & & \\
\hline CCVCCCC & flights* & & & \\
\hline CCVCCCCC & twelfths* & & & \\
\hline CCCVCCCCC & strengths* & & & \\
\hline
\end{tabular}

Note: $\dagger$ Since Chinese and Japanese are syllabic languages, they do not allow for this kind of presentation without the support of Pinyin. However, they are included in this table for comparison purposes. The classification is based on pronunciation, which is different from the orthographic syllabic structures. This is why the Chinese and Japanese parts are presented in gray.

* Although the spelling of the words accords with the syllabic structures, the number of phonemes are different from that of graphemes because some digraphs have one phoneme (e.g., thing [ or a silent (e.g., strike).

** The syllable has a null-sound place holder consonant in the onset position; hence, the consonant should be treated differently in orthography from other consonants that have solid sound values. 


\subsection{Asian Students' Performance in Core Subjects}

There are scholars who have speculated the negative impact of the Chinese writing systems on Asian students' academic achievement. Hannas (1997, 2003) is one of them, as seen in his remarks that "... East Asians are wasting their youth and resources learning about language. Notwithstanding their efforts, the system's inherent difficulties predispose those societies using Chinese characters to low literacy rates and other maladies, especially among the young..." (Hannas, 1997, p. 125). He goes on saying "[c]reativity is snuffed out by the task of memorizing endless rules that lead nowhere. Science fails to take root. Liberal ideals are lost on the mass of people whose reading skills are inadequate..." (Hannas, 1997, 125). Hannas (2003) asserts in his book entitled The Writing on the Wall: How Asian Orthography Curbs Creativity that Asians' inability to be creative stems from the character-based writing system. Although Hannas may have a point in terms of the Western perspective of creativity, the results of an international comparison study of 15-year old students' reading, math, and science skills generally show otherwise. If Hannas is right about the negative effect of Chinese characters, Chinese and Japanese students' performance of reading and other subjects (due to reading being a foundational means for learning other subjects) should be behind that of European and American students. However, Asian students' performance in reading, math, and science rank on top among their international peers ${ }^{16}$.

The Program for International Student Assessment (PISA), orchestrated by the Organization for Economic Cooperation and Development (OECD), reports international comparison data of 15-year-old students' reading, mathematics, and science every three years since 2000. There are other international comparative assessment programs, such as the Progress in International Reading Literacy Study (PIRLS; assessing fourth-graders literacy skills every 5 years since 2001) and the Trends in International Mathematics and Science Study (TIMSS; assessing math and science achievement of grades 4 and 8 every 4 years since 1995). However, PISA is the one which includes all countries of interest here. PISA measures general and functional skills as well as cross-curricular competencies, including collaborative problem solving. PISA 2015 reports students' core academic skills in more than 70 countries and education systems. Table 5.5. shows the rank in the subjects of reading, math, and science among students of the three East-Asian countries and American students.

In 2009 and 2012, the Chinese data relied solely on students from Shanghai, which is the largest and wealthiest city in China. The most current 2015 data include three more provinces other than Shanghai given that Shanghai is not

\footnotetext{
${ }^{16} \mathrm{~A}$ reviewer asked whether time spent studying and being tutored was controlled in the international comparison study. PISA and PIRLS did not control for the variable. East Asians tend to spend extra-time studying English and math by getting external help through learning institutes or tutoring, but hardly reading.
} 
Table 5.5. East-Asian and American Students' Performance on the Core Subjects in an International Study (PISA)

\begin{tabular}{|c|c|c|c|}
\hline & Reading & Math & Science \\
\hline \multicolumn{4}{|l|}{$\underline{2015}$} \\
\hline Chinese (B-S-J-G*) & 27 & 6 & 9 \\
\hline Japanese & 8 & 5 & 2 \\
\hline Korean & 7 & 7 & 11 \\
\hline American & 24 & 40 & 25 \\
\hline \multicolumn{4}{|l|}{$\underline{2012}$} \\
\hline Chinese (Shanghai) & 1 & 1 & 1 \\
\hline Japanese & 4 & 7 & 4 \\
\hline Korean & 5 & 5 & 7 \\
\hline American & 25 & 36 & 28 \\
\hline \multicolumn{4}{|l|}{$\underline{2009}$} \\
\hline Chinese (Shanghai) & 1 & 1 & 1 \\
\hline Japanese & 8 & 9 & 5 \\
\hline Korean & 2 & 4 & 6 \\
\hline American & 17 & 31 & 22 \\
\hline
\end{tabular}

Note: * This refers to the four PISA participating China provinces: Beijing, Shanghai, Jiangsu, and Guangdong. When this chapter was written, the 2015 data was the most recent one available. The PISA's 2018 test results are now available

representative of China. The average reading score of China in 2015 is not as good as those of math and science. Other countries that use Chinese characters, such as Hong Kong and Singapore, excel in reading. Singapore marks the top in rank in the three subjects in 2015. It is difficult to come to a conclusion with only one-year data that Chinese students' reading skills lag behind their peers in most other Asian countries.

Based on the comparison data, globally speaking, there is little evidence that Chinese characters impede East-Asian students' performance, as Hannas (2003) claims. When Hong Kong and Singapore where Chinese is used are included in the pool of the comparison, the data become even stronger as students in those countries excel in all subjects. Overall, 15-year old American students are not on par with their East-Asian counterparts in the three core subjects. This indicates that, even though it takes six years on average to master them, Chinese characters per se do not hinder East-Asian students' learning. Especially Japanese students mark high in rank in reading, whose written language comprises a large portion of Chinesederived Kanji.

Hannas (1997) also makes comments on the Koreans as follows: "Rather than an indictment of present orthographic practice, the ability of Koreans to excel in today's competitive world without writing Chinese characters is a clear tribute to the superiority of the hangul script..." (p. 137). He seems to be partially right with regard to the Hangul alphabetic effect, considering the rapid economic growth shown since the Korean War (1950-1953). However, he fails to identify the specific areas on which the script has had an effect. Hanna $(1997,2003)$ seems to highlight 
the negativity of Chinese characters based on value judgment. Importantly, the effect of interest is not about good-or-bad value judgment on the scripts but about differences among those scripts.

Logan (2004) claims that Chinese mathematics is more algebraic than geometric and that Chinese logic primarily relies on analogy and inductive reasoning, which is different from Western logic that is based on matching and deductive reasoning. $\mathrm{He}$ continues to note that, although the Chinese showed advances in some areas such as technology, arts, philosophy, and religious thought, the Western Industrial Revolution was different from Chinese technology.

There is a myth in U.S. K-12 settings and the U.S. general public that Asian students excel in math. The myth also claim that Asian students are only good at arithmetic not in geometry. In a similar vein, Nisbett (2003) questions "[w]hy do nonlogical Asians tend to do so much better in math and science than Americans?" (p. 189). He identifies a misconception as well as differences in cultural values and practices between the East and the West. He indicates that "[w]e don't actually find East Asians to have trouble with formal logic, we just find them to be less likely to use it in everyday situations where experience or desire conflicts with it" (p. 188). He also points out that cultural norms of emphasizing the Middle Way (this concept is discussed in the next chapter) do not go hand in hand with logic and that the traditional East-Asian culture places high values on literature, arts, and music as the proper pursuits of the cultured person. This is consistent with Taylor and Taylor's (2014) point that China's and Korea's long-lasting civil-service examinations, which was a royal ticket for the highest rung within the social hierarchy, only focused on Confucian Classics, neglecting math and science. In relation to Logan's (2004) claim that Asian thinking is more concrete, practical, and less abstract due to the effect of less abstract logographic characters, Nisbett (2003) states that " ... Asian superiority in math and science is paradoxical but scarcely contradictory" (p. 189).

\subsection{Implications of the Script Differences for Script Relativity}

If McLuhan's "the medium is the message" is right, the medium through which we read should have a substantial impact on what we read, how we read, and how we process the message. Script is a vehicle through which our reading takes place. Reading is at the apex of information processing, which involves multifaceted cognitive functions, automaticity, and being difficult to suppress reading when text is visible. Chinese, Japanese, and Korean writing systems are all East-Asian but different scripts in the face of collectively shared culture among the three nations. This fact provides a unique opening for considerations of script effects above and beyond 
linguistic relativity and culture. This becomes conceivable when we reflect on the intrinsic differences among the Chinese, Japanese, and Koreans as well as their cultures in terms of social norms, philosophies, and especially religious choices as mentioned in the Prologue. In order to further understand the foundations and manifestations of East-Asian cultures, the next chapter discusses the multiple underpinnings of variations between the East and the West in terms of extrinsic and intrinsic differences.

Open Access This chapter is licensed under the terms of the Creative Commons Attribution 4.0 International License (http://creativecommons.org/licenses/by/4.0/), which permits use, sharing, adaptation, distribution and reproduction in any medium or format, as long as you give appropriate credit to the original author(s) and the source, provide a link to the Creative Commons license and indicate if changes were made.

The images or other third party material in this chapter are included in the chapter's Creative Commons license, unless indicated otherwise in a credit line to the material. If material is not included in the chapter's Creative Commons license and your intended use is not permitted by statutory regulation or exceeds the permitted use, you will need to obtain permission directly from the copyright holder.

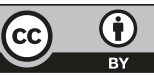

